\title{
Leptin Measurement
}

National Cancer Institute

\section{Source}

National Cancer Institute. Leptin Measurement. NCI Thesaurus. Code C74866.

The determination of the amount of leptin hormone present in a sample. 